\title{
СОВРЕМЕННЫЕ СОЦИАЛЬНО ОРИЕНТИРОВАННЫЕ ПРАКТИКИ И КОНСТРУИРОВАНИЕ ИДЕНТИЧНОСТИ: ОБЛАСТИ ВЗАИМОДЕЙСТВИЯ
}

\author{
Елена Владимировна Гиниятова, \\ eginiyatova@yandex.ru
}

\begin{abstract}
Национальный исследовательский Томский государственный университет, Россия, 634050, пр. Ленина, 36.
\end{abstract}

Елена Владимировна Гиниятова, кандидат философских наук, старший научный сотрудник Лаборатории методологии и теории культуры Института искусств и культуры Национального исследовательского Томского государственного университета.

\begin{abstract}
Актуальность статьи связана с проблемой конструирования идентичности современного человека. Кризис идентичности как явление, зародившееся во второй половине ХХ в., только обостряется и усиливается в современном культурном пространстве, чему способствуют новые научные направления (например, квир-исследования). В то же время можно декларировать смену общества потребления на культуру просьюмеризма. В связи с этим изменяются и подходы к формированию идентичности. Цель: рассмотреть, как современные социально ориентированные практики культуры просьюмеризма влияют на конструирование идентичности современного человека. Выводы. Социальное предпринимательство и hand-таdе как практики, получившие распространение в просьюмерской культуре, становятся формами работы с идентичностью человека и могут способствовать его самоопределению и самоидентификации.
\end{abstract}

Ключевые слова: Кризис идентичности, идентичность, общество потребления, просьюмеризм.

Современный человек достаточно давно находится в ситуации кризиса собственной идентичности. В философском дискурсе XX в. эта проблема косвенно отразилась через «смерть автора/субъекта» $[1,2]$, размывание структуры целостной идентичности и представления о себе через противостояние «Оно» и «Сверх-Я» [3] и т. д. В свою очередь, так называемые квир-исследования, ставящие под сомнение гендерную идентичность и бинарную гендерную систему, окончательно утверждают представление об идентичности как о конструкторе, который человек вынужден сам «собирать» на протяжении жизни, не имея укорененности даже в биологической, половой идентификации с определенной исторически выстроенной системой ценностных ориентиров и стратегий поведения в социуме [4]. Столкновение с «множественными» идентичностями, выбором/конструированием гендерно-половой идентичности только обостряет чувство экзистенциальной пустоты у человека. Это может происходить в том числе и потому, что, актуализировав/открыв для себя возможность выбора (а не предзаданности) идентичности и ее множественность, находясь в достаточно инертном социуме, человек становится заложником «неуспешной» социализации [5].

Действительно, для конструирования собственной идентичности социум имеет важнейшее значение, что было отмечено П. Бергманом и Т. Лукманом, Дж.Г. Мидом, П. Бурдье [5-8]. При этом, при смене общественных парадигм, изменяется и способы актуализации и конструирования собственной идентичности. Для начала следует демаркировать общество потребления $[9,10]$ и сменяющую его культуру просьюмеризма. 
В чем же состоит принципиальная разница между двумя этими формами организации социаума? Общество потребления ориентировано на потребительский подход. В конструировании идентичности это проявляется как потребление сформированных смысловых идентификаторов. Особенно хорошо эта стратегия реализуется в маркетинге, когда стратегии продвижения/продажи формируются не столько на основании качества товаpa, сколько через возможность самовыражения человека, его покупающего. Именно поэтому Д. Аакер [10], известный специалист в сфере маркетинга, к главным ценностям бренда, который он может предложить потребителю, относил ценность самовыражения. Таким образом, в рамках общества потребления человек потреблял не вещи, а смыслы, позволяющие ему самоопределиться и сконструировать собственную идентичность.

Культура просьюмеризма ориентирована на деятельный, активно преобразующий подход человека к миру. Понятие «просьюмер» (субъект, создающий товары, услуги и опыт для собственного пользования) вводит Э. Тоффлер [11], как элемент нового типа экономики, в которой будет преодолеваться разрыв между производителем и потребителем. Анализ современных социально ориентированных практик, таких как hand-made и социальное предпринимательство показало, что их массовое распространение и популяризация стали возможны только в условиях формирования культуры просьюмеризма. Так, практика hand-made формируется как альтернатива потребительскому отношению к миру, ведь в рамках этой практики человек преодолевает экзистенциальную лакуну через рукотворность и одухотворенность вещей [12]. В то же время практика hand-made получила такое распространение именно в условиях кризиса идентичности и напрямую связана с самовыражением как формой конструирования собственной идентичности. Социальное предпринимательство, находясь между предпринимательством и благотворительностью, является междисциплинарным феноменом, имеющим в своем основании стремление человека решить социальную проблему. Это также вписывается в стратегию просьюмеризма - ведь активное переживание социума становится ключевым триггером для преобразования реальности и формой конструирования себя. Важной чертой, выявленной в процессе анализа данных современных практик, становится возможность их капитализации. Именно возможность, потому что получение прибыли от данных социально ориентированных и реализуемых практик не является основной целью, это сопутствующий эффект при их тиражировании и распространении.

Таким образом, современные социальные практики, которые были рассмотрены выше, становятся актуальными трендами по трем причинам:

1) смена парадигмы общества потребления на культуру просьюмеризма: потребительского подхода - на производственно-потребительский;

2) преодоление экзистенциального кризиса через «рукотворность» и «приручение реальности»;

3) преодоление кризиса идентичности через новые формы конструирования идентичности (в рамках практики hand-made - через самовыражение, в рамках практики социального предпринимательства - через центрирование в личном пространстве человека социальной проблемы с последующим ее решением).

Исследование выполнено за счет гранта Российского научного фонда (проект №19-18-00237). 


\section{СПИСОК ЛИТЕРАТУРЫ}

1. Барт Р. Смерть автора. URL: http://philology.ru/literature1/barthes-94e.htm (дата обращения 10.10.2019).

2. Фуко М. Герменевтика субъекта. - СПб.: Наука, 2007. - 677 с.

3. Фрейд 3. Я и Оно. - М.: Эксмо-Пресс, 2016. - 864 с.

4. От дисфории до брендинга: словарь важных гендерных терминов. URL: https://www.wonderzine.com/wonderzine/life/life/217975-gender/ (дата обращения 10.10.2019).

5. Бергер П., Лукман Т. Социальное конструирование реальности. Трактат по социологии знания. URL: https://evolkov.net/soc.psychol/Berger.P.Luckmann.T/ (дата обращения 10.10.2019).

6. Mead G. H. Mind Self \& Society. - Annoted Edition by Daniel R. Huebner and Hans Joas, The University of Chicago Press, Chicago and London, 2015. - 536 p.

7. Бурдье П. Начала. - M.: Socio-Logos, 1994. - 287 c.

8. Дебор Г. Общество спектакля. - М.: Логос, 1999. - 224 с.

9. Бодрийяр Ж. Общество потребления. - М.: АСТ, 2019. - 320 с.

10. Аакер Д. Создание сильных брендов. - М.: Гребенников, 2008. - 440 с.

11. Тоффлер Э. Третья волна. - М.: АСТ, 2010. - 800 с.

12. Збинякова Т.В. Эволюция образа вещи в культуре: дис. ... канд. филос. наук. - СПб., 2000. - 153 с.

Поступила 20.11.2019 2. 
UDC 101.1:316.628:316.728

\title{
MODERN SOCIALLY-ORIENTED PRACTICES AND IDENTITY DESIGN: AREAS OF INTERACTION
}

\author{
Elena V. Giniyatova, \\ eginiyatova@yandex.ru
}

National Research Tomsk State University, 36, Lenin avenue, Tomsk, 634050, Russia.

Elena V. Giniyatova, Cand. Sc., senior researcher, National Research Tomsk State University.

The relevance of the article is related to the problem of constructing the identity of a modern person. The crisis of identity, as a phenomenon that originated in the second half of the twentieth century, is only exacerbated and intensified in the modern cultural space, which is facilitated by new scientific directions (for example, queer research). At the same time, it is possible to declare a change in consumer society to a culture of prosumism. In this regard, the approaches to formation of identity are changing. The aim of the research is to consider how modern socially oriented practices of the culture of prosumerism affect the construction of the identity of a modern person. Conclusions. Social entrepreneurship and Hand-made, as practices that have spread in prosumer culture, become forms of work with a person's identity, and can contribute to its self-determination and self-identification.

Key words: Crisis of identity, identity, consumer society, prosumerism.

Research was carried out with a grant from the Russian Science Foundation (project no. 19-18-00237).

\section{REFERENCES}

1. Bart R. Smert avtora [Death of the author]. Available at: http://philology.ru/literature1/barthes-94e.htm (accessed 10 October 2019).

2. Fuko M. Germenevtika subekta [Hermeneutics of the subject]. St. Petersburg, Nauka Publ., 2007. 677 p.

3. Freid Z. Ya i Ono [I and It]. Moscow, Eksmo-Press Publ., 2016. 864 p.

4. Ot disforii do brendinga: slovar vazhnykh gendernykh terminov [From dysphoria to branding: a glossary of important gender terms]. Available at: https://www.wonderzine.com/wonderzine/life/life/217975-gender/ (accessed 10 October 2019).

5. Berger P., Luckman T. Sotsialnoe konstruirovanie realnosti. Traktat po sotsiologii znaniya [Social construction of reality. A treatise on the sociology of knowledge]. Available at: https://evolkov.net/soc.psychol/Berger.P.Luckmann.T/ (accessed 10 October 2019).

6. Mead G. H. Mind Self \& Society. Annoted Edition by Daniel R. Huebner and Hans Joas, The University of Chicago Press, Chicago and London, 2015, 536 p.

7. Bourdieu P. Nachala [Beginning]. Moscow, Socio-Logos Publ., 1994. 287 p.

8. Debor G. Obshchestvo spektaklya [Society of the play]. Moscow, Logos Publ., 1999. 224 p.

9. Baudrillard J. Obshchestvo potrebleniya [Consumer society]. Moscow, AST Publ., 2019. 320 p.

10. Aaker D. Sozdanie silnykh brendov [Creation of strong brands]. Moscow, Grebennikov Publ., 2008. 440 p.

11. Toffler E. Tretya volna [The third wave]. Moscow, ACT Publ., 2010. 800 p.

12. Zbinyakova T.V. Evolyutsiya obraza veshchi v culture. Dis. Kand. nauk [The evolution of the image of a thing in culture]. St. Petersburg, 2000. 153 p.

Received: 20 November 2019. 